\title{
TRES PROBLEMAS DE ATRIA SOBRE LOS CONCEPTOS JURÍDICOS ILUSTRADOS EN EL CONCEPTO DE DERECHO SUBJETIVO
}

\author{
THREE PROBLEMS OF ATRIA ON THE LEGAL CONCEPTS \\ ILLUSTRATED IN THE CONCEPT OF SUBJECTIVE RIGHT
}

\author{
María Beatriz Arriagada Cáceres*
}

\begin{abstract}
RESUMEN: El primer objetivo de este trabajo es demostrar que la teoría de Fernando Atria sobre los conceptos jurídicos presenta tres problemas: (i) asume que los conceptos jurídicos no son puramente estructurales sin especificar en qué consiste su estructura, (ii) afirma que la estructura de un concepto jurídico hace probable el desempeño de una función que es naturalmente improbable sin especificar el concepto de probabilidad utilizado y disfraza que la tesis auténticamente defendida es que determinadas estructuras deben desempeñar determinadas funciones y (iii) es una filosofía política del derecho disfrazada de teoría jurídica. El segundo objetivo de este trabajo es ilustrar estos problemas en el concepto atriano de derecho subjetivo.
\end{abstract}

Palabras clave: Conceptos jurídicos, derechos subjetivos, derechos fundamentales.

ABSTRACT: The first aim of this paper is to demonstrate that Fernando Atria's theory of legal concepts presents three problems:(i) assumes that legal concepts are not purely structural without specifying what their structure consists, (ii) states that the structure of a legal concept makes it probable to perform a function that naturally is improbable without specifying the concept of probability used and disguises the authentically defended thesis is that certain structures must perform certain functions and (iii) is a political philosophy of law disguised as legal theory. The second aim of this paper is to illustrate these problems in the Atria's concept of subjective right.

Keywords: Legal concepts, rights, fundamental rights.

\section{INTRODUCCIÓN}

La discusión jurídica sobre la posibilidad de equiparar a los derechos sociales con los derechos liberales (civiles y políticos) puede ser leída como una controversia acerca del concepto jurídico de derecho subjetivo.

\footnotetext{
* Doctora en Derecho. Profesora e investigadora del Departamento de Teoría del Derecho de la Universidad Diego Portales e investigadora del Centro de Investigaciones de Filosofía del Derecho y Derecho Penal, Escuela de Derecho, Universidad de Valparaíso, Chile. Dirección postal: República 112, Santiago Centro. Dirección de correo electrónico: mbeatriz.arriagada@gmail.com y maria.arriagada@udp.cl.

Este trabajo corresponde a resultados del proyecto financiado por el Fondo Nacional de Desarrollo Científico y Tecnológico, FONDECYT de iniciación No 11150372 "Análisis de la tensión entre el concepto y el fundamento de los derechos fundamentales a partir de las ideas de Fernando Atria sobre las diferencias entre los derechos civiles y políticos y los derechos sociales".
} 
En contra de la equiparación, se afirma que los derechos sociales no son derechos en sentido estricto porque no son judicialmente exigibles ${ }^{1}$. A favor de la equiparación se sostiene que los derechos sociales son auténticos derechos porque la juridicidad de un derecho no depende de su garantía judicial que solo es un instrumento para su protección ${ }^{2}$.

Cada una de estas tesis se sustenta en un concepto diferente de derecho subjetivo. La tesis que afirma que los derechos sociales son auténticos derechos se sustenta en el concepto kelseniano de derecho reflejo ${ }^{3}$ equivalente al concepto hohfeldiano de derecho subjetivo en sentido propio ${ }^{4}$. De acuerdo con este concepto, un individuo tiene un derecho subjetivo cuando, con fundamento en una norma jurídica regulativa, otro u otros se encuentran a su respecto obligados a comportarse de cierta manera. La que afirma que los derechos sociales no son derechos en sentido estricto se apoya en el concepto kelseniano de derecho subjetivo en sentido técnico ${ }^{5}$ que puede ser descrito como una conjunción de los conceptos hohfeldianos de derecho subjetivo y potestad ${ }^{6}$. De acuerdo con este concepto, un individuo tiene un derecho subjetivo cuando, con fundamento en una norma de competencia, tiene la potestad de exigir judicialmente el cumplimiento de lo que, con fundamento en una norma regulativa, otro u otros le deben.

Las dos tesis expuestas han sido típicamente vinculadas a dos visiones ideológicamente opuestas sobre el fundamento político-moral para conferir derechos subjetivos. La defensa de la equiparación de los derechos sociales con los liberales se atribuye a una ideología progresista y la tesis opuesta a una ideología conservadora ${ }^{7}$. Así, el concepto jurídico de derecho subjetivo reflejo se vincula con una justificación progresista y el de derecho subjetivo en sentido técnico con una justificación conservadora.

Este esquema se quiebra cuando la defensa progresista de los derechos sociales inicialmente fundada en el concepto de derecho subjetivo reflejo se convierte paradójicamente en un auténtico alegato en favor de su transformación en derechos subjetivos en sentido técnico ${ }^{8}$. La idea de que los derechos sociales deben ser tan justiciables como los liberales era ya la nueva ortodoxia del constitucionalismo9 cuando Fernando Atria identificó la paradoja envuelta en el discurso progresista.

En contra de este discurso, la tesis de Atria afirma que los derechos sociales no pueden, a diferencia de los derechos liberales expresarse en el lenguaje de los derechos subje-

\footnotetext{
1 Por ejemplo, BöcKenförde (2001) [1993] p. 80 y Hesse (2001) [1994] p. 98. En la misma línea, se afirma que los derechos sociales no son derechos verdaderos sino derechos sobre el papel; GUASTINI (1999) [1996] pp.185-186 y 188-189.

2 Por ejemplo, Páramo (2000) p. 368, Cruz (2004) p. 85 y Pérez luño (2011) pp. 66 y ss

3 Kelsen (1991) [1960] pp. 139-143.

4 Hohfeld (2010) [1913] pp. 35-40.

KeLsen (1991) [1960] pp. 146-149 y 152.

6 Hohfeld (2010) [1913] pp. 35-40, 50-60.

Por ejemplo, RuIz (1994) pp. 652-654. Sobre conservadurismo y progresismo ver BonazZI (2007) [1983] pp. 318-323.

8 Ejemplos del esfuerzo por justificar la justiciabilidad de los derechos sociales se encuentran en ABRAMOVICH Y Courtis (2004) p. 38, nota No37 de ese trabajo; BASTIDA (2007) pp. 116-119 y RossetTi (2010) p. 121, nota No54 de ese trabajo.

9 Michelon (2004) p. 8.
} 
tivos. Hablar de derechos sociales es una contradicción en los términos. Reformulada una década más tarde, la tesis afirma que los derechos sociales, a diferencia de los derechos liberales, son injertos anómalos, una subversión del concepto de derecho subjetivo y un criterio de distribución diferente del mercado ${ }^{10}$.

Al mostrar que esta tesis no implica adoptar una postura conservadora ${ }^{11}$, Atria no solo modificó las coordenadas de la discusión. Su objetivo inicial fue demostrar que el concepto jurídico de derecho subjetivo es incompatible con el fundamento político-moral de los derechos sociales. Pero una década más tarde se convirtió claramente en un objetivo político, inaugurándose un auténtico discurso contracultural que ha derivado en la propuesta de un nuevo modelo y un cambio de paradigma ${ }^{12}$ que ha logrado influencia en políticas legislativas de muy debatido éxito ${ }^{13}$.

La tesis de Atria sobre los derechos sociales y sus diferencias con los derechos liberales está comprometida con la tesis según la cual el concepto jurídico de derecho subjetivo está necesariamente ligado a determinado fundamento político-moral ${ }^{14}$. A esta tesis subyace una tesis sobre lo que son los conceptos jurídicos y una tesis sobre el tipo de explicación que los hace inteligibles ${ }^{15}$.

El primer objetivo de este trabajo es demostrar que la teoría de Atria sobre los conceptos jurídicos presenta tres problemas: (i) asume que los conceptos jurídicos no son puramente estructurales sin especificar en qué consiste su estructura; (ii) afirma que la estructura de un concepto jurídico hace probable el desempeño de una función que naturalmente es improbable sin especificar el concepto de probabilidad utilizado y disfraza la tesis auténticamente defendida: determinadas estructuras deben desempeñar determinadas funciones y (iii) es una filosofía política del derecho disfrazada de teoría jurídica. El segundo objetivo del trabajo es ilustrar estos problemas en el concepto atriano de derecho subjetivo.

La primera parte del texto resume la teoría de Atria sobre los conceptos jurídicos. La segunda parte muestra su aplicación al concepto atriano de derecho subjetivo. La tercera parte identifica y analiza los tres problemas recién mencionados y verifica su aparición en el concepto atriano de derecho subjetivo.

\footnotetext{
10 La propuesta teórica de Atria sobre las diferencias entre los derechos liberales y sociales se formula en dos etapas. La primera corresponde a dos artículos publicados en 2004. El primero contiene la formulación original y el segundo la complementa respondiendo a las críticas publicadas en el mismo volumen; ATRIA (2004a) y Atria (2004b) en respuesta a Bernal (2004); Cruz (2004) y Gargarella (2004). La segunda etapa corresponde principalmente a dos libros; Atria (2013) y Atria (2014).

11 Lo novedoso es que la negación del carácter vinculante de las disposiciones de derechos sociales se haga compatible con una profunda fidelidad a las doctrinas socialistas; Bernal (2004) p. 118. Atria admite que su tesis de que los derechos sociales no pueden ser judicialmente exigibles parece alinearlo con la constitución chilena de Pinochet y procura explicar esto es solo apariencia; Atria (2014) p. 35, nota $\mathrm{N}^{\circ} 13$ de ese trabajo

12 Ver, además de Atria (2013) y Atria (2014), Atria et al. (2013).

13 La idea de gratuidad universal en la educación es un claro ejemplo.

14 Arriagada (2014a) pp. 265-267 y 281.

15 Desarrolladas en Atria (2016).
} 


\section{1.- LA TEORÍA DE ATRIA SOBRE LOS CONCEPTOS JURÍDICOS}

La teoría de Atria sobre los conceptos jurídicos puede sintetizarse identificando las dos tesis que la sustentan: una tesis sobre lo que son los conceptos jurídicos y una tesis sobre lo que es una explicación de los mismos.

\subsection{TESIS SOBRE LO QUE SON LOS CONCEPTOS JURÍDICOS: ENTRE ESTRUCTURA Y FUNCIÓN}

Los conceptos jurídicos son, según Atria, estructuras o instituciones que hacen probable el desempeño de una función o idea preinstitucional que, sin la mediación de la estructura, es improbable ${ }^{16}$. Son institucionales, funcionales y estructuralmente mediados. Esto significa que: (i) no tienen existencia preinstitucional, (ii) se definen por una función o idea pre-institucional cuyo desempeño es naturalmente improbable y (iii) las instancias a las que los conceptos se aplican son estructuras que hacen probable el desempeño de una función que naturalmente es improbable y dichas estructuras solo son identificables e inteligibles a partir de esa función.

Para explicar la conexión entre estructura y función, Atria distingue la pregunta por la inteligibilidad del concepto (pregunta ontológica o por la definición del concepto) de la pregunta por su modo de operación (pregunta de individuación o por las instancias a las que el concepto de aplica). Estas dos preguntas deben mantenerse separadas porque la función de un concepto funcional se hace probable cuando la identificación de las instancias a las que se aplica es estructural y no funcional ${ }^{17}$.

La función es explicativamente fundamental respecto de la estructura porque el sentido de esta es hacer probable aquella; pero la estructura hace probable la función porque, en cuanto a su operación, es ciega u opaca a ella. En relación con la función, la estructura es racionalmente dependiente (la estructura, en sus propios términos, es arbitraria o irracional; solo es inteligible a partir de la función) y operativamente autónoma (la estructura, en su forma de operación, es autosuficiente; por eso puede mediar la función) ${ }^{18}$.

Hacer inteligible la estructura de un concepto es mostrar su conexión con (el modo en que ella hace probable) la función ${ }^{19}$. Si bien en la individuación de un concepto prima la estructura, para identificarla y hacerla inteligible es necesario atender a la función ${ }^{20}$.

\footnotetext{
16 Atria (2016) pp. 145-150, 153-154, 332 y 355.

17 Se puede, por ejemplo, admitir que la "ley" no es lo que sustantivamente va en el interés de todos (función), sino lo que ha sido aprobado por cierto procedimiento (estructura) porque la individuación de una ley se hace por referencia a su estructura, no a su función. La dimensión individuatoria del concepto es mediada por una estructura porque, si el concepto tuviera una relevancia de individuación inmediata, tendríamos que concluir que las decisiones que formalmente se presentan como leyes, en cuanto adoptadas por órganos y procedimientos legislativos, no son en realidad leyes si no son ejercicios de autogobierno democrático de los ciudadanos. No obstante, sería un error concluir que el concepto de ley es estructural y no funcional, pues el sentido del procedimiento legislativo es hacer probable que la ley represente el interés de todos; AtRIA (2016) pp. 145-147.

18 Atria (2016) pp. 148-150.

19 ATria (2016) p. 149.

20 Atria (2016) pp. 203-204.
} 


\subsection{TESIS SOBRE LA EXPLICACIÓN DE LOS CONCEPTOS JURÍDICOS: LA VÍA MEDIA ATRIANA}

La segunda tesis que sustenta la teoría de Atria se refiere al modo de hacer inteligibles los conceptos jurídicos. Atria intenta una suerte de vía media entre dos extremos que son objeto de crítica: el Positivismo jurídico en su versión analítica y el Neoconstitucionalismo.

Al primero se le critica que, al dar por sentado su objeto al modo en que la física da por sentado el concepto de agua, se queda en la superficie de los conceptos, renunciando a su comprensión más sofisticada. Al ignorar la función que los hace inteligibles, la reflexión jurídica es incapaz de mostrar la conexión interna entre las instituciones y algo que importe. Una teoría que se jacta de ignorar todo menos lo que efectivamente hacen los funcionarios que corresponda opaca la función de las instituciones e induce a los participantes a entenderlas como puras estructuras, como conceptos nominales ${ }^{21}$.

El Neoconstitucionalismo es criticado porque su desprecio hacia las formas institucionales fomenta una regresión hacia un sistema en el cual no hay aplicación sino únicamente creación del derecho. Este desprecio conduce a una auténtica involución hacia formas jurídicas premodernas que en las circunstancias actuales implica la disolución del derecho ${ }^{22}$.

El Positivismo analítico se equivoca al entender los conceptos jurídicos como puramente estructurales ignorando la relevancia de la función que los hace inteligibles. El Neoconstitucionalismo se equivoca al atender exclusivamente a la función y pasar por alto la relevancia de la estructura y el carácter institucional del derecho.

La vía media atriana puede definirse como una teoría del derecho que aspira a mostrar que las estructuras son inteligibles a partir de las funciones que desempeñan: "Una explicación de un concepto jurídico es una especificación de a) una idea preinstitucionalmente identificable, cuyo desempeño es naturalmente improbable; b) las razones por las cuales ese desempeño es naturalmente improbable, y c) el modo en que una estructura neutraliza o compensa las causas de esa improbabilidad identificadas en (b) y hace así probable el desempeño de la idea preinstitucional identificada en (a)"23.

Asumiendo que el desafío de la teoría del derecho no es obtener clarificación conceptual sino inteligibilidad institucional, Atria admite que su punto de partida es un acto de fe en la inteligibilidad de lo realmente existente. A su juicio, ello supone introducir una dimensión que suele estar ausente de la reflexión teórica: el hecho de que hay funciones que necesitan ser desempeñadas porque su ejercicio, a través de una estructura determinada, está legitimado ${ }^{24}$.

Esto significa que entre función y estructura debe haber correspondencia (la estructura debe hacer probable la función), pero no en un sentido moral o normativo sino fáctico de que si no hay correspondencia la habrá. Por tanto, si entre estructura y función hay contradicción, la situación será inestable y esta inestabilidad inestabilidad tenderá a solucio-

\footnotetext{
21 Atria (2016) pp. 89-94, 149-150, 153-154 y 230-231.

22 Atria (2016) pp. 27-28 y 67-75, 240 y 261 nota $\mathrm{N}^{\circ} 12$ de este trabajo.

23 Atria (2016) p. 154.

24 Atria (2016) pp. 230-231.
} 
narse de cualquiera de dos formas: (i) la estructura será reinterpretada de modo de hacerla corresponder con la función o, más probablemente, (ii) la función pasará a ser vista como externamente vinculada a la estructura, esto es, como vinculada en un sentido puramente normativo que pronto será entendido como un mito, en cuyo caso la función caerá en obsolescencia y la estructura comenzará a desempeñar una función distinta ${ }^{25}$.

\section{EL CONCEPTO ATRIANO DE DERECHO SUBJETIVO}

Las tesis de Atria sobre lo que son conceptos jurídicos y el modo de hacerlos inteligibles permiten comprender su concepto de derecho subjetivo ${ }^{26}$. Si como todos los conceptos jurídicos es funcional y estructuralmente mediado, el sentido de su estructura es hacer probable el desempeño de una función que naturalmente es improbable.

\subsection{LA PRIMERA FORMULACIÓN ATRIANA DEL CONCEPTO DE DERECHO SUBJETIVO}

La tesis según la cual los derechos sociales no pueden ser derechos en sentido jurídi$\mathrm{Co}^{27}$ está comprometida con un determinado concepto de derecho subjetivo. Un derecho subjetivo es, según Atria, la posición en la que se encuentra un individuo que tiene la potestad para decidir si la obligación que otro u otros tienen, en interés del primero, será o no coactivamente exigida ${ }^{28}$.

Además de puntualizar que este concepto coincide con el concepto kelseniano de derecho subjetivo en sentido técnico y que el término potestad está siendo utilizado en el sentido de Hohfeld ${ }^{29}$, Atria reconoce que parece estar suscribiendo una teoría ecléctica (entre interés y voluntad) ${ }^{30}$. Sin embargo, no advierte que esto es incompatible con análisis como los de Kelsen y Hohfeld cuyo punto de partida es el rechazo de cualquier intento de definir los derechos subjetivos sobre la base de los bienes, valores o necesidades sustanciales que ellos protegen y justifican su adscripción y no sobre la base de su estructura o forma.

De acuerdo con Kelsen, las teorías del interés y de la voluntad y cualquier combinación de ambas incurren en el error de intentar poner de manifiesto lo que el derecho protege o reconoce (sustancia) en lugar de la protección (forma) que interesa al jurista ${ }^{31}$. En el mismo sentido, Hohfeld advierte la importancia de diferenciar las relaciones puramente jurídicas de los hechos físicos y psíquicos que las hacen surgir; los elementos jurídicos de

\footnotetext{
25 Atria (2016) pp. 231-232.

26 Un análisis completo de todas tesis defendidas por Atria en relación con las diferencias entre los derechos liberales y sociales puede verse en ARRIAGADA (2014b) pp. 255-282.

27 Atria (2004a) pp. 15, 22 y 51- 52 y Atria (2004b) p. 147.

28 "[P] ara que en sentido jurídico podamos hablar de un derecho subjetivo es necesario que una persona, (i) tenga una obligación (ii) cuya exigibilidad está jurídicamente mediada por la declaración de voluntad de otra; y (iii) que sea reconocida o creada por el derecho en atención al interés de esa otra”; Atria (2004a) p. 23. Ver también pp. 22, 25, 43 y 47.

29 Atria (2004a) p. 22 y nota $\mathrm{N}^{\circ} 20$ de ese trabajo.

30 Atria (2004a) p. 23 y nota $\mathrm{N}^{\circ} 23$ de ese trabajo.

31 Kelsen (1987) [1923] pp. 510 y 539 y (1991) [1960] pp.145-150.
} 
los elementos no jurídicos ${ }^{32}$. Como su proyecto no es sustantivo sino definicional ${ }^{33}$, su marco analítico es neutral frente al debate entre las teorías del interés y de la voluntad ${ }^{34}$ que en realidad son dos ideologías sobre el fundamento político-moral para adscribir derechos subjetivos ${ }^{35}$.

Atria afirma que en el concepto jurídico derecho subjetivo está implicada la idea liberal de que el interés individual protegido por el derecho triunfa frente a las aspiraciones comunitarias $^{36}$. Este concepto está necesariamente ligado a un interés y a una voluntad individuales.

La idea liberal implicada en el concepto jurídico de derecho subjetivo justificaría que los derechos civiles y políticos puedan, a diferencia de los sociales, expresarse en el lenguaje de los derechos subjetivos. Los primeros pueden ser concebidos como derechos naturales porque en su formulación no hay referencia a la vida en comunidad. Como para especificar su contenido tanto activo como pasivo es suficiente atender a la posición del individuo aislado, del hecho de que alguien tenga un derecho, se sigue que todos y cada uno de los individuos restantes tienen el deber de no interferir con la conducta lícita del otro ${ }^{37}$. Los derechos sociales, en cambio, no pueden ser concebidos como derechos naturales porque su formulación no es posible sin referencia a la vida en comunidad. La especificación de su contenido activo no es una especificación completa de su contenido pasivo porque la pregunta sobre quién es el obligado solo puede responderse cuando los individuos viven en comunidad y esta, como un todo, se preocupa del bienestar de cada uno de sus miembros ${ }^{38}$.

Desde esta perspectiva, los intentos de la doctrina progresista están condenados al fracaso. Hacer exigibles a los derechos sociales implica dessocializarlos o privatizarlos, esto es, convertirlos en auténticas demandas liberales ${ }^{39}$. El derecho no es lo suficientemente neutral o dúctil para expresar sin distorsiones el conflicto político entre liberalismo y socialismo que se traduce en la confrontación entre derechos civiles y políticos y derechos sociales ${ }^{40}$. El fracaso de los intentos de torcer la forma del derecho para adecuarlo al contenido de los derechos sociales evidenciaría la contradicción implicada en la noción misma de derechos sociales ${ }^{41}$.

Atria no solo cree que la estructura del concepto jurídico de derecho subjetivo excluye ciertos contenidos (los derechos sociales no pueden ser derechos). También cree que esta estructura está necesariamente ligada a determinado contenido: un interés que es egoísta porque se opone e impone frente a los intereses colectivos. El fundamento socialista de los derechos sociales es incompatible con el concepto jurídico de derecho subjetivo porque este

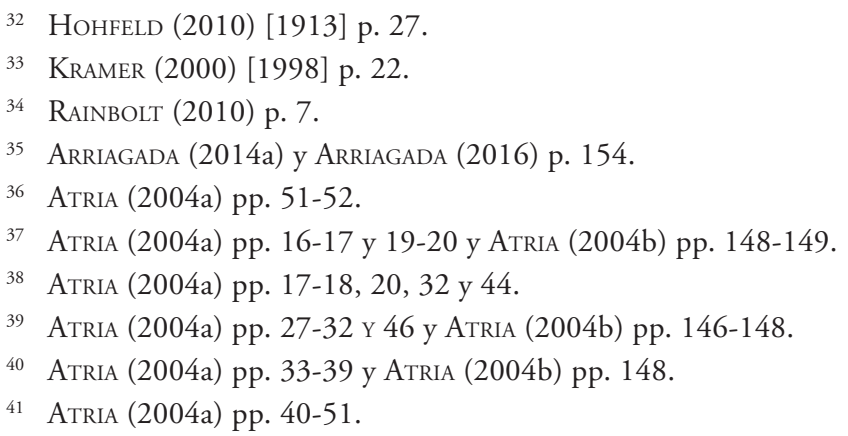


no puede separarse de su fundamento liberal. La estructura de este concepto hace probable que determinados intereses individuales triunfen frente a los intereses colectivos.

\subsection{2.- LA SEgUnda FORMULACión ATRIANA DEL CONCEPTO DE DERECHO SUbJETIVO}

Una década más tarde, Atria intenta mejorar la situación de los derechos sociales sin renunciar a su comprensión socialista ni a la crítica a la doctrina progresista. Su estrategia es atribuir a los derechos sociales la misión de transformar el lenguaje que solo permite la expresión de los derechos civiles y políticos.

En lugar de limitarse a comprobar la contradicción implicada en la noción de derechos sociales, Atria afirma que las demandas socialistas formuladas como derechos son injertos anómalos que dejarán de ser anómalos, tanto si resultan asimilados a las categorías burguesas como si logran ser capaces de transformar el derecho burgués construido sobre la base de la idea de derecho subjetivo propia de una una teoría liberal que ve la realización humana como algo fundamentalmente individual ${ }^{42}$.

La creencia de que los derechos sociales tienen esta potencial capacidad transformadora tiene su origen en la idea de que la noción misma de derechos sociales es ya una subversión del concepto de derecho subjetivo. El sentido de estos derechos es volver la teoría del derecho subjetivo en contra del derecho subjetivo mostrando que una idea individualista puede ser subvertida para transformarse en una idea socialista ${ }^{43}$.

Como los derechos sociales expresan la idea de que hay ciertos aspectos del bienestar de cada uno que son responsabilidad de todos, tales aspectos o intereses deben ser removidos del mercado. No deben ser entendidos como derechos a prestaciones específicas, determinables ex-ante, de una vez por todas y en términos universales. Deben ser entendidos como un criterio público de distribución de los recursos disponibles que, a diferencia del criterio de mercado, descansa en el reconocimiento de la igualdad de todos. En cuanto derechos de ciudadanía, los derechos sociales son una idea que provee un punto de referencia que nos guía lentamente en el aprendizaje de lo que nos debemos recíprocamente y su contenido se desarrolla en la historia mediante decisiones políticas que representan el interés de $\operatorname{todos}^{44}$.

Vistos así, los derechos sociales están vinculados a la idea de libertad, con la importante consecuencia de que el socialismo ahora puede ser entendido como el legítimo heredero del liberalismo ${ }^{45}$. ¿Cómo es posible este radical cambio de opinión si no se ha renunciado a la comprensión socialista ni a la crítica hacia la doctrina progresista? La respuesta debiera buscarse en el concepto de derecho subjetivo que no parece ser entendido exactamente del mismo modo que hace una década.

Junto con reiterar que el poder de exigibilidad es su característica principal, Atria afirma que en los derechos subjetivos pueden distinguirse dos caras: (i) la cara opresiva representada por el hombre egoísta separado de otros hombres y de la comunidad y (ii) la

\footnotetext{
42 Atria (2014) pp. 45-46, 52-53, 57 y 65-66 y Atria (2013) p. 149-151 y 180.

43 Atria (2014) pp. 38-43 y 45 y Atria (2013) pp. 148-151.

44 Atria (2013) pp. 34, 152 y 159-187 y Atria (2014) pp. 51-61 y 65-66 y 69-77.

45 Atria (2013) p. 92.
} 
cara emancipatoria representada por la negación de que un individuo pueda ser usado para beneficio de otro ${ }^{46}$. Este cambio permite redirigir la crítica hacia el neoliberalismo ${ }^{47}$ pues solo dejando a salvo al liberalismo resulta posible asignar a los derechos sociales la tarea de transformar el derecho liberal que consiste en radicalizar la cara emancipatoria de los derechos subjetivos $^{48}$.

Después afirma que decir que alguien tiene un derecho a algo es en principio lo mismo que decir que: (i) es ilícito que no reciba aquello a lo que tiene derecho y (ii) cuando es imposible satisfacer todos los derechos, la cuestión de cómo se distribuyen los recursos es una cuestión pública que concierne a todos, no una cuestión privada entre el deudor y cada acreedor ${ }^{49}$. Su argumento consiste en que, cuando se trata de derechos sociales, la prioridad de estas dos dimensiones presentes en todos los derechos se invierte " $[\mathrm{L}] \mathrm{a}$ principal dimensión de decir que algo es un derecho social no es que de eso se desprenda una especificación precisa de qué es aquello a lo que cada uno tiene derecho, sino la publificación del problema de la distribución" ${ }^{50}$.

Esto parece explicar que Atria mantenga la idea de que los derechos sociales son diferentes a los ahora llamados derechos de libertad negativa por la forma en que son identificados y determinado su contenido. Los derechos de libertad negativa protegen intereses que pueden ser identificados en el estado de naturaleza. Como son derechos naturales y su sujeto pasivo es universal, la especificación completa de su aspecto activo es inmediatamente una especificación de su aspecto pasivo (quién tiene qué deber). Los intereses protegidos por los derechos sociales no pueden ser identificados del mismo modo porque son derechos del ciudadano situado. Una especificación de su aspecto activo (del interés al que el derecho sirve) no es suficiente para especificar su aspecto pasivo (un deber de proteger ese interés $)^{51}$.

La crítica de Atria se focaliza ahora en el contractualismo cuya comprensión de la asociación política no dejaría espacio para los auténticos derechos sociales (entendidos como derechos de ciudadanía) sino solamente para derechos liberales a un mínimo ${ }^{52}$. Pero no queda claro si hay un concepto de derecho subjetivo que permita la expresión de los derechos liberales y sociales. Aquí es donde importa comprender qué es lo que Atria quiere

\footnotetext{
46 Atria suscribe la idea de Proudhon de que toda institución realmente existente tiene una cara emancipatoria y una cara opresiva; ATRIA (2013) pp. 147-148.

47 El neoliberalismo, como el conservadurismo, acepta la desigualdad como un hecho natural; AtRIA (2013) pp. 92 y ss.

48 Atria cree, con Proudhon, que volver la teoría de la institución contra la institución significa utilizar una de sus caras para destacar los déficits de la otra, mostrando que el camino hacia el socialismo no pasa por la abolición de las instituciones liberales sino por la radicalización de su cara emancipatoria. El mercado, por ejemplo, no es solo un criterio de distribución (dimensión opresiva), sino también la forma institucional de un espacio de intercambio no forzado (dimensión emancipatoria). Los derechos sociales están dirigidos a asegurar la libertad para todos y su éxito mostraría que la dimensión emancipatoria del mercado puede ser igual para todos y no solo para los privilegiados; ATRIA (2013) pp. 147-148 y 152-159.

49 Atria (2014) pp. 57 y 66.

50 ATria (2014) pp. 55-61 y 65-66.

51 Atria (2014) pp. 48 y 51-52.

52 Atria (2014) pp. 52-53.
} 
decir cuando afirma que el sentido y la tarea de los derechos sociales es transformar el derecho burgués o liberal, subvertir el concepto de derecho subjetivo o volver la teoría del derecho subjetivo en contra del derecho subjetivo mostrando que una idea individualista puede ser subvertida para transformarse en una idea socialista.

Si la tarea de los derechos sociales es transformar el derecho burgués o liberal, el éxito de esta tarea parece poder sintetizarse en las siguientes palabras de Atria: "Aunque la idea que fundamenta los derechos sociales es opuesta a la que fundamenta el derecho liberal, el lenguaje que utiliza para expresarla no es el de la oposición (el cual no podría ser entendido por la racionalidad del cuerpo receptor), sino el de la continuidad. Pero continuidad transformadora: los derechos sociales como la completa realización de lo que hay de importante en los derechos que son centrales para el derecho liberal (los derechos civiles y políticos)" 53 .

De acuerdo con Atria, la denominación misma de derechos sociales muestra ya la subversión del concepto de derecho subjetivo. El primer paso en la tarea de volver la teoría del derecho subjetivo en contra del derecho subjetivo habría sido sustituir la idea de señorío de la voluntad por la de la protección jurídica de un interés de un individuo. Este cambio en la comprensión habría hecho posible expresar en el lenguaje de los derechos la idea socialista de que hay ciertos intereses o aspectos del bienestar de cada uno que son responsabilidad de $\operatorname{todos}^{54}$. El paso siguiente sería usar la noción de derechos sociales para pensar instituciones que transformen el derecho burgués ${ }^{55}$.

Como los derechos subjetivos tienen ahora dos diferentes caras (opresiva y emancipatoria) y dos diferentes dimensiones (es ilícito no recibir aquello a lo que se tiene derecho y la publicación del problema de distribución), la subversión aludida podría entenderse afirmando que la estructura de los derechos subjetivos hace probable una función distinta de la originalmente pensada o querida al momento de la formulación del concepto ${ }^{56}$. La función inicial (los intereses individuales triunfan sobre los intereses colectivos) pasaría a ser vista como externamente vinculada a la estructura y esta última tendría que ser reinterpretada de modo de hacerla corresponder con la nueva función desempeñada (la idea de que hay ciertos aspectos del bienestar que son responsabilidad de todos).

En esta línea, se podría argumentar que Atria afirma que: (i) los defensores progresistas de los derechos sociales se equivocan al creer que la principal dimensión que se juega en su reconocimiento es su exigibilidad judicial y (ii) para que los derechos sociales puedan ser judicialmente exigibles es necesario leer en su aspecto activo una especificación suficien-

\footnotetext{
53 Esta sería la importancia de la afirmación de Marshall según la cual los derechos (civiles, políticos y sociales) aparecen progresivamente en la historia de suerte que cada paso desarrolla más plenamente el sentido del paso anterior, la idea de ciudadanía; Atria (2014) p. 46.

54 Atria (2013) pp. 148-149. El paso desde la idea de derecho subjetivo como un señorío de la voluntad retratada por Hobbes, Spinoza y Kant a la idea de que se trata de un interés protegido por el derecho puede ser atribuido a Ihering; ver Hobbes (1980) [1651] pp. 106 y 118-119 (Capítulos XIV y XV); SpInoza (1986) [1670] pp. 334-352 (Capítulo XVI); KANT (2005) [1797] pp. 41-42 (párrafo No 232); y Ihering (2011) [1865], Tomo IV, p. 821 (Libro II, Segunda parte, Título I). Sobre la evolución del significado del derecho subjetivo ver, por ejemplo, los trabajos de Villey (1976).

55 Atria (2013) pp. 149-151.

56 En similar sentido, Gargarella alude a la capacidad de los derechos, así como de otras creaciones humanas, de independizarse de las limitadas aspiraciones de sus creadores; GARGARELLa (2004) pp. 62-63.
} 
temente precisa del deber que ellos imponen cuyo contenido se desarrolla en la historia ${ }^{57}$. Estas afirmaciones permiten inferir que, aunque la exigibilidad judicial no es la principal dimensión de los derechos sociales, estos podrían llegar a ser exigibles una vez especificado su contenido pasivo o el deber que ellos imponen mediante su desarrollo en la historia y conforme a un criterio público de distribución.

Este cambio en el modo de entender la función del concepto de derecho subjetivo no solo habría permitido que las aspiraciones socialistas de los derechos sociales pudieran expresarse en el lenguaje de los derechos (primer paso de la subversión) sino también modificar la comprensión de los derechos civiles y políticos (segundo paso de la subversión). En lugar de ser entendidos como reclamos egoístas que se oponen e imponen a los intereses colectivos, cabría considerar que el interés de todos es que ciertos bienes como la vida, la libertad o la autonomía política estén protegidos para todos y cada uno de los miembros de la comunidad.

Pese a que algunas de las afirmaciones de Atria parecen apuntar en esta dirección, no está dispuesto a revisar su comprensión de los derechos liberales que considerando como derechos del individuo aislado cuya formulación es posible sin referencia a la vida en comunidad. Tampoco está dispuesto a admitir abiertamente que los derechos sociales pueden transformarse en derechos judicialmente exigibles.

La consideración de los derechos sociales como injertos anómalos que dejarán de ser anómalos incluye la posibilidad de que su capacidad subversiva sea neutralizada mediante su secuestro por las categorías burguesas. Si son convertidos en algo que puede ser protegido y exigido en términos individualistas, dejan de ser sociales porque ya no expresan la idea socialista de realización recíproca y de que hay aspectos del bienestar que son responsabilidad de todos. Solamente expresan la idea individualista del hombre egoísta unida a la idea de que es necesario asegurar un mínimo a todos que justifique su obligación de someterse al derecho ${ }^{58}$.

Mostrar que una idea individualista puede ser subvertida para transformarse en una idea socialista no significa entonces mostrar que la estructura del concepto de derecho subjetivo puede hacer probable la realización de una idea socialista. La estructura del concepto de derecho subjetivo no puede hacerla probable. Solo puede convertirla en una idea individualista, lo que representa el fracaso de los derechos sociales.

Esto prueba que el concepto atriano de derecho subjetivo no cambió porque no cambió la forma en que se entiende su estructura y su función. La neutralización del potencial transformador de los derechos sociales mediante su secuestro por las categorías burguesas (su conversión en derechos judicialmente exigibles) no es otra cosa que la solución a un caso de contradicción entre estructura y función. Como la estructura de los derechos subjetivos no puede hacer probable la idea socialista de los derechos sociales, estos se transforman en derechos liberales y la idea socialista no pasa de ser un mito.

Estamos entonces de vuelta en el inicio. El fundamento socialista de los llamados derechos sociales es incompatible con el concepto jurídico de derecho subjetivo porque este

\footnotetext{
7 Atria (2014) p. 65.

58 Atria (2014) pp. 52-53 y 65 y Atria (2013) pp. 149-151 y 180.
} 
no puede separarse de su fundamento liberal. La estructura de este concepto hace probable que determinados intereses individuales triunfen frente a los intereses colectivos.

\section{TRES PROBLEMAS DE ATRIA SOBRE LOS CONCEPTOS JURÍDICOS Y SU APARICIÓN EN EL CONCEPTO DE DERECHO SUBJETIVO}

\section{1 ¿EN QUÉ CONSISTE LA ESTRUCTURA DE UN CONCEPTO JURÍDICO?}

La tesis de Atria sobre lo que son los conceptos jurídicos parte de la premisa de que estos no pueden ser puramente estructurales, esto es, definidos exclusivamente por su estructura.

Para justificar esta premisa, Atria esgrime dos argumentos. El primer argumento consiste en que las estructuras no sirven para individuar un concepto porque las mismas estructuras pueden encontrarse en conceptos diferentes, sin que por ello dejen de ser diferentes. El segundo argumento afirma que, debido al carácter institucional de los conceptos jurídicos, las características estructurales elegidas se justifican por referencia a su uso (esas características han sido tradicionalmente utilizadas para identificar determinado objeto) o bien por referencia a una función (esas estructuras, y no otras, hacen probable el desempeño de cierta función). En el primer el concepto es nominal y en el segundo es funcional ${ }^{59}$.

Ambos argumentos cometen la falacia de asumir implícitamente lo que pretenden demostrar. Al primer argumento se puede responder que en la afirmación de que determinados conceptos son diferentes está implicada la afirmación de que sus estructuras son diferentes. La afirmación según la cual las mismas estructuras pueden encontrarse en conceptos diferentes es necesariamente falsa dado que los conceptos se definen precisamente por su estructura. Al segundo argumento se puede responder que la afirmación de que la elección de las características estructurales de un concepto puede justificarse por referencia a su uso o a una función, asume que las razones para elegir la estructura de un concepto forman parte del concepto y, por tanto, que los conceptos jurídicos no pueden ser puramente estructurales.

La tesis según la cual los conceptos jurídicos no son puramente estructurales no implica, según Atria, descartar la noción de clase estructural. El agua, por ejemplo, puede caracterizarse estructuralmente por su composición molecular porque nuestro uso del concepto de agua asume (y puede asumir) que el agua tiene una existencia anterior a ese uso o a nuestras teorías del agua; nuestra explicación de la naturaleza del agua deja al agua tal como estaba antes de nuestro intento de explicarla. Esto no es posible tratándose de conceptos jurídicos que no tienen existencia preinstitucional y, por tanto, una naturaleza anterior al análisis que pueda servir como criterio de corrección por vía de la experimentación ${ }^{60}$.

En esto Atria tiene toda la razón. Pero la única conclusión que puede obtenerse es que la estructura de un concepto jurídico no es como la estructura del agua. Que las ca-

59 Toda teoría del derecho puramente estructural es incapaz de responder dos preguntas cruciales: (i) sobre la identificación de las estructuras que son declaradas decisivas (cuáles son las estructuras), y (ii) sobre la relevancia de esas estructuras (por qué ciertas estructuras y no otras son las que definen el concepto); ATRIA (2016) pp. 136-145 y 165 .

${ }^{60}$ Atria (2016) pp. 85-86 y 142. 
racterísticas estructurales de los conceptos jurídicos sean elegidas y no estén naturalmente determinadas no autoriza a concluir que estos conceptos no pueden ser definidos exclusivamente por su estructura.

Las discusiones sobre la estructura de los conceptos suelen estar determinadas por un compromiso implícito con uno de dos modelos diferentes: (i) el modelo reductivo o de la contención, según el cual los conceptos son estructuras complejas compuestas de otros conceptos o (ii) el modelo conectivo o inferencial, según el cual los conceptos son estructuras complejas que se relacionan con otros $\operatorname{conceptos}^{61}$. Pero nada de esto aparece en la explicación de Atria.

El problema es que nunca aclara qué entiende por la estructura de un concepto jurídico al punto que las estructuras son definidas a partir de las funciones que (se supone) desempeñan. Así, por ejemplo, afirma que "La institución legislativa es la estructura cuya finalidad es hacer probable la identificación de lo que va en interés de todos; la institución judicial es una cuya finalidad es hacer probable que los casos que le sean sometidos sean decididos dando a cada uno lo suyo, etc.”62. La legislación, la jurisdicción y la administración son estructuras informadas por principios diferentes (democrático, de independencia y comisarial), cada uno de los cuales hace probable el desempeño de la respectiva función ${ }^{63}$.

El concepto atriano de derecho subjetivo ofrece una oportunidad inmejorable para ilustrar este problema. Porque, dejando a un lado las funciones, ideas o elementos extrajurídicos que Atria incluye en su definición, es posible reconocer una estructura compleja compuesta de varios conceptos más simples. En términos puramente estructurales, el concepto atriano de derecho subjetivo es definido como la posición en la que se encuentra un individuo con potestad para decidir si la obligación de otro será o no coactivamente exigi$\mathrm{da}^{64}$.

Elucidar la estructura de un concepto jurídico de derecho subjetivo supone identificar la norma o las normas del derecho objetivo que adscriben esa posición jurídica a una clase de sujetos. Observadas las normas jurídicas desde su dimensión subjetiva, el derecho subjetivo es la posición o situación jurídica subjetiva y la norma es su fundamento jurídi$\mathrm{co}^{65}$. Para identificar las normas jurídicas que adscriben posiciones jurídicas es necesario analizar las disposiciones que las expresan y el modo en que estas disposiciones son interpretadas. Identificados de este modo los diferentes tipos de normas que intervienen en la adscripción de posiciones jurídicas subjetivas, es posible reconocer que hay diversos conceptos de derecho subjetivo y analizar su estructura ${ }^{66}$.

Dado que el concepto atriano de derecho subjetivo es estructuralmente idéntico al concepto kelseniano de derecho subjetivo técnico cuyo fundamento jurídico es una norma

\footnotetext{
61 Margolis y Laurence (1999) p. 5. Que sean diferentes no implica que sean incompatibles y que no puedan combinarse; STRaWson (1997) [1992] pp. 65-71 y Moreso (2004) pp. 19-20.

62 Atria (2016) p.154.

63 Atria (2016) pp. 189-218.

64 Atria (2004a) p. 22.

65 Ver por ejemplo KelSEN (1987) [1923] pp. 507 y 539-540 y GUASTINI (1999) [1996] pp. 180-182 y GUASTINI (2016) p. 83.

${ }^{66}$ Ver, por ejemplo, los análisis estructurales de HoHfeld (2010) [1913] y Kelsen (1991) [1960] pp. 138 y ss.
} 
regulativa y una norma de competencia, la primera crítica que puede formularse es que Atria asume que los llamados derechos civiles y políticos tienen esta estructura. Porque una adecuada explicación de las diferentes posiciones jurídicas incluidas bajo ese rótulo es mucho más compleja.

Los derechos políticos no son, bajo ningún punto de vista, derechos subjetivos en sentido técnico porque no se fundamentan en normas regulativas sino en normas de competencia que adscriben cierta clase de individuos la potestad de participar en las decisiones sobre la producción de las normas del derecho. Por su parte, los llamados derechos civiles son al menos de dos tipos: (i) son potestades de participación de política de cuyo ejercicio depende la validez general o particular de las normas producidas por las autoridades públicas y (ii) son derechos subjetivos que reflejan obligaciones de abstención de cuyo cumplimiento depende la licitud de las acciones fácticas del Estado. En cuanto potestades de participación política no reflejan obligaciones porque son adscritos únicamente por normas de competencia y, por tanto, no son derechos subjetivos en sentido técnico. En cuanto derechos subjetivos son adscritos por normas regulativas, pero suelen estar garantizados por normas de competencia que confieren a sus titulares la potestad de reclamar judicialmente frente al incumplimiento de las obligaciones estatales. Solo en este caso son derechos subjetivos en sentido técnico.

El solo hecho de que Atria no advierta la complejidad de los derechos civiles y políticos evidencia la deuda que su teoría tiene en relación con la estructura de los conceptos jurídicos. Pero este déficit también puede apreciarse en su intento de explicar los derechos sociales.

Atria insiste en que convertir a estos derechos en exigibles implica abandonar la idea socialista de que hay ciertos aspectos del bienestar que son responsabilidad de todos. Sin embargo, nada dice sobre la estructura jurídica que permite la expresión de esta idea o que hace probable su desempeño. Si la principal dimensión de los derechos sociales es que la distribución de los derechos es algo que concierne a todos, cabe preguntar cuál es la estructura que permite expresar la dimensión no principal consistente en que es ilícito que alguien no reciba aquello a lo que tiene derecho.

A menos que Atria siga pensando que los derechos sociales no pueden ser derechos en sentido jurídico, la única opción posible sería decir que las demandas socialistas pueden expresarse jurídicamente como derechos subjetivos reflejos adscritos por normas regulativas. Paradójicamente, la posición de Atria terminaría confluyendo con el punto de partida de la doctrina progresista antes de su alegato en favor de la justiciabilidad de los derechos sociales: los derechos sociales son derechos en sentido jurídico porque la existencia de un derecho no depende de su garantía judicial.

Atria no es claro sobre la adopción de esta posición, pero si este fuera el caso habría que concluir que está utilizando dos conceptos de derecho subjetivo con estructuras y funciones diferentes: (i) el concepto kelseniano de derecho subjetivo en sentido técnico intentaría explicar, aunque sin éxito, los derechos civiles y políticos y (ii) el concepto kelseniano de derecho reflejo procuraría explicar los derechos sociales.

La razón por la cual Atria no es claro sobre la estructura de los derechos sociales es la misma por la cual no consigue explicar adecuadamente la estructura de las diversas posicio- 
nes jurídicas que están ocultas bajo la noción de derechos civiles y políticos. Su error consiste en no enfrentar el problema de la estructura del concepto o los conceptos de derecho subjetivo que usa. Esta omisión impide justificar la conclusión de que estos conceptos no son puramente estructurales que Atria da por demostrada.

\subsection{LA CONEXIÓN INTERNA ENTRE ESTRUCTURA Y FUNCIÓN EN LOS CONCEPTOS} JURÍDICOS: UNA EXIGENCIA NORMATIVA DISFRAZADA DE PROBABILIDAD

Asumiendo que los conceptos jurídicos no pueden ser puramente estructurales, Atria argumenta que el supuesto inicial de todo esfuerzo por desarrollar una teoría es que son funcionales. El fracaso de este empeño sería entender que son nominales porque ello equivaldría a afirmar que el hecho de que usemos ciertas palabras para designar ciertas formas jurídicas es arbitrario, carece de racionalidad y se explica únicamente porque siempre se ha hecho así67.

Atria modifica ligeramente la distinción de Moore entre clases naturales, nominales y funcionales según si sus elementos comparten la misma naturaleza, denominación o función ${ }^{68}$ para clasificar las clases en naturales y nominales según si se definen por algo interno o externo a ellas. Mientras las clases nominales carecen por definición de naturaleza, las clases naturales pueden ser estructurales o funcionales según si lo que es interno a ellas es una estructura o forma o una función o sustancia. Las instancias de una clase funcional comparten así una misma naturaleza ${ }^{69}$.

Los conceptos jurídicos son, según Atria, funcionales, aunque no puramente funcionales porque entre su función y su estructura hay una conexión interna. Esta conexión no es puramente normativa porque en ese caso sería externa, pero tampoco es una relación de necesidad sino de probabilidad ${ }^{70}$. La pregunta relevante y carente de respuesta es qué significa "probable" e "improbable" cuando se afirma que la estructura de un concepto hace probable el desempeño de una función que naturalmente es improbable o cuál es el concepto de probabilidad utilizado.

El uso de un término tan controvertido como el de probabilidad sin precisar cuál es exactamente su sentido es cuestionable ${ }^{71}$. Atria afirma que las estructuras facilitan el desempeño de una función que sin ellas es improbable y que la contradicción entre estructura y función es inestable porque tiende a ser resuelta ${ }^{72}$. Pero no parece sensato pensar que está entendiendo la probabilidad en el sentido empírico de una propensión física, disposición o

\footnotetext{
67 Atria (2016) pp. 145 y 230.

68 Moore (1997) pp.19-20.

69 Atria (2016) pp. 136-137. Para Moore las clases funcionales tienen, igual que las clases naturales como la clase del agua o del oro, una naturaleza que es compartida por cada una de las instancias que pertenecen a la clase. Que algo sea un estómago depende de que cumpla la función que es constitutiva de los estómagos (procesar la comida) sin que importe cuál sea su estructura; Moore (1997) p. 20.

70 La estructura hace probable pero no necesario el desempeño de la función, al punto que la primera puede ser incluso un obstáculo para el desempeño de la segunda; Atria (2016) p. 157.

${ }_{71}$ Tradicionalmente, los filósofos de la probabilidad han reconocido cinco principales interpretaciones o conceptos de probabilidad; clásico, lógico, subjetivista, frecuentista y propensista; HÁJEK (2012).

72 Atria (2016) p. 149 y 332.
} 
tendencia de un determinado tipo de situación física para producir un resultado de cierta clase o de la frecuencia relativa con la que ocurre cierto resultado dentro de un conjunto actual y finito de resultados ${ }^{73}$.

Tampoco es sensato pensar que Atria esté aludiendo a la probabilidad en el sentido clásico. Este enfoque asigna probabilidades en ausencia de cualquier evidencia o en presencia de evidencia equilibrada simétricamente. La idea guía es que, en tales circunstancias, la probabilidad se comparte por igual entre todos los resultados posibles, de modo que la probabilidad de un evento es simplemente la fracción del número total de posibilidades en las que ocurre el evento. Este concepto es especialmente adecuado para los juegos de azar que por su propio diseño crean tales circunstancias; por ejemplo, la probabilidad de que al lanzar un dado se obtenga un número par se expresa como $3 / 6$, donde 3 indica el número de casos o resultados favorables y 6 indica el número de casos o resultados posibles ${ }^{74}$.

La única opción plausible parece ser que Atria entienda la probabilidad en el sentido subjetivo de grado de creencia, convicción o confianza de ciertos agentes racionales ${ }^{75}$ en el desempeño de una función por una estructura. Este tipo de concepto de probabilidad podría explicar que Atria afirme que hay funciones que necesitan ser desempeñadas porque su ejercicio, a través de una estructura determinada, está legitimado. Esta legitimación podría interpretarse como la existencia de un alto grado de confianza en que determinada estructura desempeñará cierta función.

Si el concepto de probabilidad es usado en este sentido subjetivo, lo criticable es que no se especifique quiénes son los agentes a los que se atribuye tan alto grado de confianza ni cómo este tendría que medirse. Estas omisiones son teóricamente inexcusables, pero la urgencia de evidenciarlas se justifica principalmente porque, bajo esta imprecisa idea de probabilidad, Atria disfraza sus ideas políticas acerca de lo que es legítimo. Su convicción de que es justo que ciertas estructuras desempeñen ciertas funciones se encubre afirmando que tales estructuras hacen probable el desempeño de tales funciones.

Como hay funciones que, según Atria, necesitan ser desempeñadas porque su desempeño a través de una estructura determinada está legitimado, entre función y estructura debe haber correspondencia (la estructura debe hacer probable la función) en el sentido fáctico de que si no hay correspondencia la habrá. La falta de correspondencia o la contradicción entre función y estructura produce un déficit de legitimación que busca o tiende a ser compensado. Este déficit hace surgir una presión adaptativa que vuelve la contradicción inestable y esta inestabilidad tiende a solucionarse de cualquiera de dos formas: (i) mediante la reinterpretación de la estructura de modo de hacerla corresponder con la función o (ii) a través de la visión de la función como vinculada a la estructura en un sentido puramente

\footnotetext{
73 Cuando es entendida como propensión o como frecuencia, la probabilidad se sitúa en el mundo; HÁJEK (2012).

74 También es insensato pensar que Atria está usando un concepto lógico de probabilidad. Las diversas variantes de este enfoque buscan determinar el grado de apoyo o confirmación que una cierta evidencia confiere a una determinada hipótesis proporcionando un marco para la inducción; HájeK (2012).

75 Sobre las diversas variantes de la interpretación subjetivistas de la probabilidad, ver HájeK (2012).
} 
normativo que pronto será entendido como un mito, en cuyo caso la función caerá en obsolescencia y la estructura comenzará a desempeñar una función distinta ${ }^{76}$.

Atria insiste en que la legitimación buscada es una necesidad política de estabilidad que no es reducible a una exigencia normativa cuya no satisfacción determina la ilegitimidad o injusticia del sistema. Pero al hacer esto procura ocultar que las dos soluciones son en realidad una: la estructura se puede reinterpretar (el concepto se puede subvertir) porque la conexión entre la estructura y la función (en los términos preinstitucionales en que Atria la entiende) no es interna sino externa, es decir, puramente normativa. La normatividad es disfrazada de probabilidad.

Si alguna duda cabe, el concepto atriano de derecho subjetivo vuelve ofrecer una oportunidad inmejorable para ilustrar el problema.

De acuerdo con la primera definición atriana, un derecho subjetivo es la posición en la que se encuentra un individuo con potestad para decidir si la obligación que otro u otros tienen, en interés del primero, será o no coactivamente exigida. Una década más tarde, Atria mantiene que la exigibilidad judicial es su característica principal, pero afirma que los derechos subjetivos tienen dos caras: opresiva y emancipatoria. A esto añade que, en todos los derechos, es posible identificar dos diferentes dimensiones: es ilícito que no se reciba aquello a lo que tiene derecho y el criterio público de distribución.

A partir de estas distinciones, Atria atribuye a los derechos sociales la tarea de transformar derecho liberal. Esta consistiría en radicalizar la cara emancipatoria de los derechos subjetivo mostrando que una idea individualista puede convertirse en una idea socialista. Como el deber que los derechos sociales imponen se especifica teniendo en cuenta el interés de todos, ellos representan la completa realización de lo que hay de importante en los derechos liberales (civiles y políticos).

Estas afirmaciones permiten inferir que la estructura del concepto de derecho subjetivo puede hacer probable una función distinta de la originalmente pensada o querida al momento de la formulación del concepto ${ }^{77}$. Se podría esgrimir que cuando se dice que todos (todas las personas, ciudadanos o compradores) tienen ciertos derechos, no se está diciendo que sus intereses individuales están por encima del interés de todos, sino que el interés de todos es que ciertos bienes estén protegidos para todos y cada uno de los miembros de la clase en cuestión ${ }^{78}$. Este cambio en el concepto de derecho subjetivo permitiría modificar la comprensión de los derechos civiles y políticos: entender que su protección se justifica porque están al servicio del bien común o del interés general ${ }^{79}$ y que estos derechos también suponen un individuo situado porque no sería posible especificar el contenido pasivo de una libertad sin presuponer la existencia de otros individuos capaces de vulnerarla ${ }^{80}$.

\footnotetext{
76 ATRIA (2016) pp. 231-233 y 332. Las transformaciones de nuestras comprensiones de la función judicial muestran, según Atria, la manera en que estructura y función se afectan recíprocamente, y que lo que hace inteligible estas transformaciones es siempre un déficit de legitimación que busca ser compensado; ver ATRIA (2016) pp. 232-250.

77 Sobre la distinción entre la formación y la aplicación de un concepto, ver GLOCK (2012) [2008] p. 265

78 CRuz (2004) pp. 79-80.

79 RAZ (2001) [1994] pp.57-68.

80 Bernal (2004) p. 100, nota $\mathrm{N}^{\circ} 11$ de ese trabajo.
} 
Atria, sin embargo, no está dispuesto a revisar su comprensión individualista, iusnaturalista y contractualista de estos derechos. Su diferencia con los derechos sociales reside supuestamente solo en una cuestión de prioridad de las dos dimensiones que estarían presentes en todos los derechos. Pero la idea de que hay ciertos aspectos de la vida humana que son responsabilidad de todos (expresada en la publificación del problema de la distribución) es una dimensión que está ausente en la descripción atriana de los derechos de libertad negativa. ¿Por qué los intereses que ellos protegen pueden ser identificados en el estado de naturaleza y su aspecto pasivo inmediatamente especificado, si su contenido también debiera ser determinado de acuerdo con un criterio público? ¿Acaso el contenido de los deberes que ellos imponen y su delimitación respeto de otros derechos no se han ido desarrollando en la historia?

Estas preguntas no tienen respuesta porque la única dimensión que está presente al momento de explicar los derechos liberales es la que permite identificar inmediatamente su contenido pasivo y que justifica su exigibilidad judicial. En contraste, cualquier intento de convertir a los derechos sociales en derechos judicialmente exigibles una vez determinado su contenido pasivo implica abandonar la idea socialista de que hay aspectos del bienestar de cada uno que son responsabilidad de todos. Como la estructura del concepto de derecho subjetivo no permite la expresión de esta idea, la contradicción solo podría resolverse convirtiéndola en una idea individualista.

Atria ni siquiera afirma que la estructura de este concepto hace probable que el interés individual triunfe frente a los intereses colectivos. Afirma que esa estructura hace necesario el desempeño de esa función. A menos que esté dispuesto a admitir que entre la estructura y la función de los conceptos jurídicos hay una conexión necesaria, sus afirmaciones solo pueden interpretarse como una exigencia normativa: determinadas estructuras deben cumplir determinadas funciones.

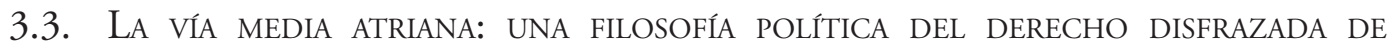 TEORÍA}

La tesis de Atria sobre el modo en que los conceptos jurídicos son inteligibles pretende ser una vía media en el sentido de ser capaz de mostrar que las estructuras son inteligibles a partir de las funciones que desempeñan. Atria cree su esquema explicativo de tres pasos no está sustantivamente comprometido porque es compatible con explicaciones alternativas acerca de cuáles son las funciones, las causas de su improbabilidad y la forma de neutralizarlas en los conceptos jurídicos ${ }^{81}$. Pero está equivocado. El concepto de derecho subjetivo es útil para ilustrar este error.

La explicación que Atria ofrece de este concepto puede reconstruirse del siguiente modo: (i) la idea preinstitucionalmente identificable cuyo desempeño es naturalmente improbable es que los intereses individuales triunfen frente a los intereses colectivos; (ii) ese desempeño es naturalmente improbable porque, en condiciones preinstitucionales, lo probable es que los intereses colectivos se impongan frente a los intereses individuales y (iii) la potestad de decidir si la obligación de otro será o no coactivamente exigida es una estruc-

81 Atria (2016) p. 157. 
tura que neutraliza o compensa las causas de la improbabilidad haciendo probable que los intereses individuales triunfen frente a los intereses colectivos.

El compromiso sustantivo de esta explicación se evidencia desde el momento en que Atria asume que el deber judicialmente exigible que los derechos subjetivos imponen se especifica con referencia a un individuo aislado y conforme a un criterio privado.

Una explicación alternativa podría afirmar, por ejemplo, lo siguiente: (i) la idea preinstitucionalmente identificable cuyo desempeño es naturalmente improbable es que ciertos bienes, como la libertad o el bienestar material, estén igualmente protegidos para todos y cada uno de los miembros de la comunidad; (ii) ese desempeño es naturalmente improbable porque, en condiciones preinstitucionales, lo probable es que la libertad y el bienestar de unos impida u obstaculice la libertad y el bienestar de otros, y (iii) la potestad jurídica de cada individuo para exigir judicialmente que cualquier otro individuo cumpla con su deber de no impedir u obstaculizar el disfrute de estos bienes es una estructura que neutraliza o compensa las causas de la improbabilidad y hace probable que la libertad y el bienestar material se distribuyan de forma igualitaria entre los miembros de la comunidad.

Atria no podría estar de acuerdo con esta explicación porque, a su juicio, una distribución igualitaria de la libertad y el bienestar material no puede hacerse probable mediante la estructura de los derechos subjetivos. Esta estructura excluye que el contenido de los deberes que los derechos imponen sea especificado teniendo en cuenta el interés de todos.

El argumento de Atria es que, para explicar un concepto, es fundamental distinguir la pregunta por su definición (pregunta ontológica) de la pregunta por las instancias a las que el concepto se aplica (pregunta de la individuación). La sugerencia parece correcta, pero esto no debiera ser otra cosa que distinguir las propiedades que caracterizan un concepto de su campo de aplicabilidad.

Un concepto puede ser definido respondiendo a la pregunta de cuáles son las propiedades necesarias y suficientes de las instancias a las que el concepto se aplica. Un derecho subjetivo puede definirse como la posición jurídica subjetiva en la que se encuentra un sujeto que, con fundamento en una norma de competencia, tiene la potestad de exigir judicialmente el cumplimiento lo que, con fundamento en una norma regulativa, otro u otros le deben. Estas propiedades son estructurales en el sentido de que su ausencia implica que la situación analizada no cuenta como un derecho subjetivo. Por su parte, las instancias a las que el concepto se aplica serán todas las situaciones que tengan estas propiedades.

La razón para elegir ciertas características estructurales y no otras puede ser que ellas hacen en algún sentido probable el desempeño de una función o idea preinstitucional deseada que de otro modo es improbable. En este sentido, la función (en los términos preinstitucionales en que Atria la entiende) puede ser útil a la inteligibilidad del origen o formación de un concepto, pero ello no implica que esa función sea parte del mismo.

Como los sistemas jurídicos suelen reflejar la moral de la comunidad jurídica respectiva, un derecho subjetivo jurídico puede ser, al mismo tiempo, un derecho subjetivo moral. Pero la tarea de elucidar un concepto jurídico de derecho subjetivo es diferente de la de identificar las razones extrajurídicas políticas y morales que justifican su atribución por 
un ordenamiento ${ }^{82}$. La primera tarea corresponda a la teoría del derecho ${ }^{83}$. La segunda a la filosofía política del derecho ${ }^{84}$.

La explicación atriana es una inconfesa filosofía política del derecho disfrazada de teoría jurídica porque, en lugar de definir los conceptos jurídicos identificando las propiedades estructurales de cada una de sus instancias, los define a partir de su posible fundamento o función preinstitucional, esto es, las razones político-morales por las cuales que algo cuente como una instancia del concepto depende de la concurrencia de esas y no de otras propiedades estructurales.

Deslumbrado por las ideas o funciones preinstitucionales cuyo desempeño puede hacerse probable gracias a las estructuras del derecho, asume que tales ideas o funciones forman parte de los conceptos jurídicos sin notar que, al hacer esto, ha ignorado la auténtica relevancia de las estructuras institucionales del derecho y no ha entendido lo que significa que el derecho sea un sistema institucionalizado.

Obsesionado con mostrar que tiene que existir una conexión interna entre esas estructuras y algo que importe, pasa por alto que, con independencia de las funciones preinstitucionales que puedan cumplir, las estructuras institucionales desempeñan auténticas funciones jurídicas y que se definen exclusivamente por las disposiciones normativas que las instituyen y por la forma en que esas disposiciones son interpretadas por quienes forman parte de la práctica institucional del derecho. Esto es lo que ha entendido muy bien la teoría que, como afirma Atria, se jacta de ignorar todo menos lo que efectivamente hacen los funcionarios que corresponda y que, por lo mismo, no tiene nada de superficial.

Atria está convencido de que una teoría que fija su atención exclusivamente en lo que los funcionarios efectivamente hacen induce a los participantes entender las instituciones como puras estructuras, como conceptos nominales. Pero esta convicción surge de confundir el punto de partida con el punto de llegada del análisis conceptual.

El análisis conceptual de la teoría analítica del derecho no es una investigación empírica destinada a describir determinados usos lingüísticos, pues estos y los problemas que ellos generan constituyen solamente un input ${ }^{85}$. Si el objetivo es explicar o reconstruir racionalmente ciertos conceptos, es fundamental que exista una primera etapa de elucidación informal destinada clarificar al máximo su alcance o el significado de los términos que se usan para designarlos en el discurso jurídico donde desempeñan un papel importante, por ejemplo, mediante ejemplificaciones y descripciones de los usos de ese término en situaciones típicas. La segunda etapa consiste en formular un nuevo concepto más preciso que el anterior $^{86}$.

Dado que es perfectamente posible seguir reglas sin poder formularlas ${ }^{87}$ pues dominar una práctica no implica dominar la teoría de esa práctica, el objetivo del análisis

\footnotetext{
Arriagada (2016) pp.153-154.

83 Particularmente a la teoría analítica del derecho; Ross (2005) [1958] pp.23-27 y CARRIó (1992) [1913] pp.

19-20.

84 Prieto Sanchís (1990) pp.17-23.

85 Moreso (2004) pp.19-20.

86 Alchourrón y Bulygin (1975) [1971] pp. 29-30.

87 Searle (2007) [1969] pp.50-51.
} 
conceptual es explicitar las reglas que gobiernan el empleo de los conceptos que utilizan los participantes al interior de una práctica ${ }^{88}$. La teoría analítica del derecho no asume con candidez los conceptos que discute, ni se queda en la superficie de los conceptos. Su propósito es explicativo, en el sentido que, sin apartarse del modo en que la práctica es comprendida por sus participantes (legisladores, jueces y juristas), debe poder decir algo sobre la práctica que aun estos participantes son incapaces de articular, pero que reconocerían si fueran advertidos por la teoría ${ }^{89}$.

La dimensión institucional no es, como cree Atria, independiente de la dimensión conceptual. Afirmar que la teoría del derecho no puede asumir una posición puramente teórica o conceptual y debe entenderse a sí misma desde una óptica institucional ${ }^{90}$ es un error porque los conceptos jurídicos son precisamente instituciones.

Desde esta perspectiva es plausible sostener que existe una conexión interna entre determinadas estructuras y determinadas funciones. La creación de hechos institucionales como los conceptos jurídicos depende de reglas constitutivas cuya forma lógica es X cuenta como $\mathrm{Y}$ en el contexto C. Consiste en asignar a una entidad (X) un nuevo estatus (Y) y, junto con él, una función o un conjunto de funciones que la entidad nombrada no poseía previamente y cuyo cumplimiento depende del acuerdo o aceptación colectivas. Pero estas funciones de estatus son poderes convencionales institucionales cuya existencia depende del reconocimiento o aceptación colectivos ${ }^{91}$. No son ideas preinstitucionales.

Esta forma básica de intencionalidad es la que constituye la estructura de los hechos institucionales con independencia de que, a un nivel micro, los participantes puedan desear el cumplimiento de todo tipo de funciones ulteriores por parte de las entidades institucionales pero que son irrelevantes para la ontología básica, y con independencia de que, a un nivel macro, los planificadores y organizadores vean las instituciones como poseedoras de funciones diferentes ${ }^{92}$.

Nada de esto implica negar las ideas preinstitucionales que pueden estar en el origen de los conceptos jurídicos ni que estas puedan ser útiles para su inteligibilidad desde una perspectiva más amplia. Que la tarea de la teoría del derecho sea distinta de la filosofía política del derecho no significa que no estén relacionadas ${ }^{93}$. Al mismo tiempo en que la teoría explica el modo en que los especialistas utilizan conceptos de aplicación general al interior

\footnotetext{
88 STRAWSON (1997) [1992] pp. 47 y ss. En términos wittgensteinianos, se trata de una compilación de recuerdos destinada a una finalidad determinada: una explicación que, sin agregar nueva información, procura resaltar las distinciones que las formas lingüísticas ordinarias suelen pasar por alto y mejorar la terminología cuando ella conduce a malos entendidos en miras de establecer un orden respecto del conocimiento que se tiene respecto del uso del lenguaje; Wittgenstein (2008) [1953] parágrafos 109, 127 y 132.

89 BIX (2006) (1995] p.169.

90 Atria (2016) p. 124 y 230.

91 SeARle (1997) [1995] pp. 58-68, 72, 83-89, 94-96, 108-122.

92 SeARle (1997) [1995] p. 111.

93 Como la elucidación conceptual no podría efectuarse con independencia de la elaboración de la teoría normativa en cuyo marco opera el concepto y la valoración no podría tener lugar sin la previa identificación conceptual de lo que se valora, se requiere de un proceso de ajustes mutuos; NiNo (1989) [1984] pp. 12-13.
} 
de su campo, muestra las relaciones que existen entre la disciplina especializada y otros asuntos intelectuales y humanos ${ }^{94}$.

El análisis de los conceptos jurídicos institucionales puede conectarse, sin confundirse, con el análisis de sus posibles fundamentos preinstitucionales. Algo muy distinto es disfrazar una filosofía política del derecho de teoría jurídica: aprovechar la fuerza y legitimidad del lenguaje de los derechos subjetivos para llevar adelante una transformación política.

\section{BIBLIOGRAFÍA CITADA}

Abramovich, Víctor y Courtis, Cristian (2004): Los derechos sociales como derechos exigibles (Madrid, Editorial Trotta).

Alchourrón, Carlos y Bulygin, Eugenio (1975) [1971]: Introducción a la metodología de las ciencias jurídicas y sociales (Buenos Aires, Editorial Astrea).

Arriagada, María Beatriz (2014a): "El concepto hohfeldiano de derecho subjetivo", Revista de Ciencias Sociales, N65: pp.13-45.

Arriagada, María Beatriz (2014b): "Derechos sociales y liberales. Un balance sobre la discusión de 2014”, Revista Discusiones, N¹5, 2: pp. 247-291.

Arriagada, María Beatriz (2015): "Las Cortes Constitucionales frente a los derechos civiles y políticos", Revista Española de Derecho Constitucional, Nº105: pp. 105-136.

Arriagada, María Beatriz (2016): “Conceptos jurídicos de derecho subjetivo”, Eunomía. Revista en Cultura de la Legalidad, N¹1: pp. 152-162.

Atria, Fernando (2004a): ¿Existen derechos sociales?”, Discusiones, N4: pp. 15-59.

Atria, Fernando (2004b): "Réplica: derecho y política a propósito de los derechos sociales," Discusiones, N4: pp.145-176.

Atria, Fernando (2013): Veinte años después. Neoliberalismo con rostro humano (Santiago, Editorial Catalonia).

Atria, Fernando (2014): Derechos sociales y educación. Un nuevo paradigma de lo público (Santiago, Editorial LOM).

Atria, Fernando (2016): La forma del derecho (Madrid, Editorial Marcial Pons).

Atria, Fernando, Larraín, Guillermo, Benavente, José Miguel, Couso, Javier y Joignant, Alfredo (2013): El otro modelo. Del orden neoliberal al régimen de lo público (Santiago, Editorial Catalonia).

Baccelli, Luca (2007) [2000]: “Derechos sin fundamento”, en Ferrajoli, Luigi (et al.), Los fundamentos de los derechos fundamentales (Trad. de Perfecto Andrés, Antonio de Cabo, Miguel Carbonell, Lorenzo Córdova, Marcos Criado y Gerardo Pisarello, Madrid, Trotta, tercera edición) pp. 197-213.

Bastida, Francisco (2007): "¿Son los derechos sociales derechos fundamentales? Por una concepción normativa de la fundamentalidad de los derechos," en Alexy, Robert et al., Derechos sociales y ponderación (Madrid, Editorial Fundación Coloquio Jurídico Europeo) pp. 103-149.

STRAWSON (1997) [1992] pp. 47-57. 
Bernal, Carlos (2004): "Fundamento concepto y estructura de los derechos sociales. Una crítica a ‘¿Existen los derechos sociales? de Fernando Atria”, Discusiones, N4: pp. 99144.

BIX, Brian (2006) [1995]: "Algunas reflexiones sobre metodología en teoría del derecho", en Teoría del Derecho: ambición y límites (Trad. de Pablo. E Navarro, Madrid, Editorial Marcial Pons) pp.167-191.

BöCKEnFÖRde, Ernst (2000) [1993]: Escritos sobre Derechos Fundamentales (Trad. de Juan Luis Resquejo e Ignacio Villaverde, Baden Baden, Editorial Nomos Verlagsgessellschaft).

Bonazzi, Tiziano (2007) [1983] “Conservadurismo" en Bobbio, Noberto (et al.), Diccionario de política (México D.F., Editorial Siglo XXI, decimoquinta edición) pp. 318-323.

Carrió, Genaro (1992): "Nota preliminar", en Hohfeld, W., Conceptos jurídicos fundamentales (Trad, de Genaro Carrió, México D.F., Editorial Fontamara) pp. 7-21.

Cruz Parcero, Juan Antonio (2004): "Leones, lenguaje y derechos. Sobre la existencia de los derechos sociales. Réplica a Fernando Atria”, Discusiones, N4: pp. 71-98.

Cruz Parcero, Juan Antonio (2007): El lenguaje de los derechos. Ensayo para una teoría estructural de los derechos (Madrid, Trotta).

Escudero, Rafael: (2010): "Estudio preliminar. Guía para los realistas analíticos: la teoría del derecho de Paolo Comanducci” en Comanducci, Paolo, Hacia una teoría analítica del derecho. Ensayos escogidos (Madrid, Editorial Centro de Estudios Políticos y Constitucionales) pp. XV-LI.

Gargarella, Roberto (2004): “Derecho y disociación. Un comentario a “¿Existen los derechos sociales?” de Fernando Atria," Discusiones, N4: pp. 61-70.

Glock, Hans-Johann, (2012) [2008]: ¿Qué es la filosofía analítica? (Trad. de Carmen García Trevijano, Madrid, Editorial Tecnos).

GuASTINI, Riccardo (1999) [1996]: Distinguiendo. Estudios de teoría y metateoría del derecho (Trad. de Jordi Ferrer, Barcelona, Editorial Gedisa).

Guastini, Riccardo: (2016) [2014]: La sintaxis del derecho (Trad. de Álvaro Núñez Vaquero, Madrid, Editorial Marcial Pons).

Hayek, Alan (2012): "Interpretations of Probability" en ZaLTA, Edward N. (edit.), The Stanford Encyclopedia of Philosophy. Disponible en: https://plato.stanford.edu/archives/ win2012/entries/probabilty-interpret/. Fecha de la consulta: 09 de junio de 2017.

Hart, H.L.A (2009) [1961]: El concepto de derecho (Trad. de Genaro Carrió, Buenos Aires, Editorial Abeledo Perrot, tercera edición).

Hesse, Conrad (2001) [1994]: "Significado de los derechos fundamentales," en Benda (et al.), Manual de Derecho Constitucional (Madrid, Editoriales Evap-Marcial Pons, segunda edición) pp. 83-115.

Hobbes, Thomas (1980) [1951]: Leviatán, o la materia, forma y poder de una república eclesiástica civil (Trad. de Manuel Sánchez Sarto, México D.F., Editorial Fondo de Cultura Económica, segunda edición).

IHERING, Rudolph (2011) [1855], El espiritu del derecho romano en las diversas fases de su desarrollo, Tomo IV (Trad. de Enrique Príncipe y Satorres, Granada, Editorial Comares, segunda edición). 
Hohfeld, Wensley (2010) [1913]: "Some fundamental legal conceptions as applied in judicial reasoning", en WHEeler COOK, W. (ed.), Fundamental legal conceptions as applied in judicial reasoning (New Heaven and London, Yale University Press) pp. 23-64.

KANT, Immanuel (2005) [1797]: La metafisica de las costumbres (Trad. de Adela Cortina de, Madrid, Editorial Tecnos, cuarta edición).

Kelsen, Hans (1987) [1923]: Problemas capitales de la teoría jurídica, 2a edición (Trad. de Wenceslao Roces, México D.F., Editorial Porrúa).

Kelsen, Hans (1991) [1960]: Teoría pura del Derecho, 2a edición (Trad. de Roberto Vernengo, México D.F., Editorial Porrúa, decimosexta edición).

Kramer, Mathew (1998) [2000]: "Rights without trimmings", en Kramer, Mathew (et al.), $A$ debate over rights (New York, Oxford University Press) pp. 7-111.

Margolis, Eric y Laurence, Stephen (1999): "Concepts and Cognitive Science" en Margolis, Eric y Laurence, Stephen (edits.), Concepts. Core redadings (Cambdridge Masachusetts, MIT Press).

Michelon, Claudio Jr. (2004): "Introducción: derechos sociales y la dignidad de la igualdad". Discusiones, No 4: pp. 7-13.

Moore, Michael (1997): Placing blame. A Theory of the Criminal Law (Oxford, Oxford University Press).

Moreso, José Juan (2004): "Prólogo", en Narváez, Maribel, Wittgenstein y la teoría del derecho. Una senda para el convencionalismo jurídico (Madrid, Editorial Marcial Pons) pp.13-24.

Moreso, José Juan y Vilajosana, José María (2004): Introducción a la teoría del derecho (Madrid, Editorial Marcial Pons, edición).

Nino, Carlos (1989): Ética y derechos humanos. Un ensayo de fundamentación (Buenos Aires, Editorial Astrea, segunda edición).

PÁramo, Juan Ramón (2000): "Derecho subjetivo”, en GARZÓn Valdés, Ernesto y LaPORTA, Francisco (edits.), El derecho y la justicia (Trotta, Madrid, segunda edición) pp. 367 394.

Pérez Luño, Alfonso (2011): Los derechos fundamentales (Madrid, Editorial Tecnos, décima edición).

Prieto SAnChís, Luis (1990): Estudios sobre derechos fundamentales (Madrid, Editorial Debate).

Rainbolt, George (2000): The concept of rights (Dordrecht, Editorial Springer).

RAZ, Joseph (2001) [1994]: "Los derechos y el bienestar individual" en La ética en el ámbito público (Trad. de María Luz Melón, Barcelona, Editorial Gedisa) pp. 57-72.

Ross, Alf (2005) [1958]: Sobre el derecho y la justicia (Trad. de Genaro Carrió, Buenos Aires, Editorial Eudeba, tercera edición).

Rossetti, Andrés (2010): "Algunos mitos, realidades y problemas en torno a los derechos sociales”, en Riвотta, Silvina. y Rossetтi, Andrés (edits.), Los derechos sociales en el siglo XXI. Un desafio clave para el derecho y la justicia (Madrid, Editorial Dykinson) pp. 101126.

Ruiz Miguel, Alfonso (1994): "Derechos liberales y derechos sociales," Doxa, números 1516: pp. 651-674. 
SeArle, John (2007) [1969]: Actos de habla. Ensayo de Filosofía del Lenguaje (Trad. de Luis M Valdés Villanueva, Madrid, Editorial, Cátedra, sexta edición).

SEARLE, John (1997) [1995]: La construcción de la realidad social (Trad. de Antoni Domènech, Barcelona, Editorial Paidós).

SpinozA, Baruch (1986) [1670]: Tratado teológico-político (Trad. de Atilano Domínguez, Madrid, Editorial Alianza)

Strawson, Peter (1997) [1992]: Análisis y metafísica (Trad. de Nieves Guasch, Barcelona, Editorial Paidós).

Villey, Michel (1976): Estudios en torno a la noción de derechos subjetivos (Valparaíso, Ediciones Universitarias).

WitTGenstein, Ludwig (2008) [1953]: Investigaciones filosóficas (Trad. de Alfonso García Suárez y Ulises Moulines, Barcelona, Editorial Crítica, cuarta edición). 